\title{
DIE DIAGNOSERING VAN STAMEL AS 'N VORM VAN PSIGONEUROLOGIESE DISFUNKSIE
}

\author{
I.C. UYS. D.Phil. (PRETORIA) \\ Dept. Spraakheelkunde, Universiteit van Pretoria.
}

\section{OPSOMMING}

Die samestelling van 'n diagnostiese program vir stamel as 'n vorm van psigoneurologiese disfunksie word gebaseer op 'n teoretiese oriëntering ten opsigte van die simptomatologiese en etiologiese verband tussen hicrdic twee sindrome. Hierdie verband word met empiriese bevindings gestaaf. ' $n$ Omvattende diagnostiese program is saamgestel met die doel om al die verskillende simptome van psigoneurologiese disfunksie, sowel as meer spesifiek, die verbale kommunikasieprobleme van stamel, uit te lig. Ten slotte word hierdie program ge-evalueer aan die hand van eksperimentele bewyse.

\section{SUMMARY}

The construction of a diagnostic programme for cluttering as a form of psychoneurological dysfunction is based on a theoretical orientation to the symptomatological and etiological relationship between these two syndromes. This relationship is confirmed by empirical findings. A comprehensive diagnostic programme is constructed with the purpose of eliciting all the different symptoms of psychoneurological dysfunction, as well as more specifically, the verbal communication problems of cluttering. Finally this programme is evaluated according to experimental findings.

Wanneer 'n navorser poog om 'n sinvolle diagnostiese program vir enige afwyking saam te stel, moet so 'n program gegrond word op 'n aanvaarbare logiese teoretiese oriëntering. Dit is egter nodig om eers 'n intensiewe studie te maak van alle relevante empiriese bevindings in verband met dié afwyking wat tot so 'n teoretiese oriëntering kan lei.

In die geval van stamel as 'n vorm van psigoneurologiese disfunksie (PND) berus 'n sinvolle diagnostiese program op

a) die bestaan van 'n simptomatologiese verband tussen stamel en PND;

b) 'n ooreenstemming in verband met die moontlike etiologiese faktore in beide gevalle;

c) empiriese bewyse dat stamel wel 'n vorm van PND is en dus as sodanig ondersoek moet word.

\section{DIE SIMPTOMATOLOGIESE VERBAND TUSSEN STAMEL EN PND}

'n Intensiewe literatuurstudie dui daarop da' PND as 'n breë diagnostiese kategorie gesien moet word, en dat dit omvattend genoeg moet wees om voorsiening te maak vir al die uiteenlopende simptome. Binne hierdie breë diagnos- 
tiese kategorieë is 'n verskeidenheid van sindrome te vinde. Dit is dus ook sinvol dat hierdie spesifieke simptoomkomplekse as sub-kategorieë herken en aanvaar sal word.

Daar bestaan egter so 'n massa publikasies oor PND dat die student verblind word deur al die losstaande, veranderlike en veelvormige simptome en gewoonlik lei dit tot teoretiese mistasting en kliniese rondtasting. In 'n onlangse navorsingsprojek is gevind dat 'n kubernetiese beskouing veral vir die spraakterapeut van groot waarde kan wees, omdat dit nie maar weer lei tot die samestelling van ' $n$ lys van bekende kenmerke nie, maar eerder aanduidend is van die verband tussen verskillende simptome. ${ }^{22}$

Dit is juis in die kubernetika wat die verband tussen PND en stamel gevind word. Volgens navorsing wat reeds gedoen is op die gebied van stamel, is daar 'n merkwaardige ooreenkoms, op by na alle vlakke, met die beeld wat deur PND geskep word. ${ }^{3,20,25}$ In hierdie gevalle is die spraakafwyking egter die middelpunt van die beskrywing van die simptoomkompleks, omdat die kenmerkendste of opvallendste simptome gesentreer is om spraak as kommunikasiemedium.

Murray $^{11}$ het die kenmerkendste simptome van PND as volg saamgevat:

1. Hiperaktiwiteit

2. Perseptuele - motoriese aantasting

3. Emosionele labiliteit

4. Algemene versteurings in koördinasie

5. Steurings van Aandag

6. Impulsiwiteit

7. Steurings van geheue en denke

8. Spesifieke leergestremdhede

9. Steurings van Spraak en Gehoor

10. Twyfelagtige neurologiese tekens en onreëlmatighede van die elektroënkefelogram.

'n Analise van die variërende simptome van stamel, veral in die lig van die bogenoemde lys van simptome, dui op die een of ander vorm van PND. Nie alle simptome, wat by verskillende stamelaars, as 'n groep voorkom, hoef as verpligtend beskou te word nie. In werklikheid kan alleenlik vier simptome as verpligtend vir die diagnose van stamel beskou word, naamlik:

a) Kort aandagspan en die daarmee gepaardgaande swak konsentrasievermoë;

b) Gebrek aan volkome bewustheid van die probleem;

c) 'n Buitensporige aantal herhalings in die spraak;

d) 'n Verswakte waarnemingsvermoë.

Die meeste simptome wat dikwels by stamelaars waargeneem word is egter opsioneel. Hierdie simptome toon 'n groot omvang, van reseptiewe, tot integrasie- en ekspressiewe probleme. Simptome wat waarskynlik die opvallendste is, sluit in die ekspressiewe of motoriese manifestasies, soos buitensporige spraakspoed, artikulasie-afwykings en 'n algemene rusteloosheid of hiperaktiwiteit. Die reseptiewe probleme is moeiliker waarneembaar, maar dra nogtans in 'n groot mate by tot die omvang van die probleem. Hier word simptome soos 
perseptuele afwykings gevind, wat kan lei tot lees- en spellingprobleme en gevolglik spesifieke skolastiese leergestremdhede. Die algemeenste opsionele simptoom van stamel is waarskynlik 'n leesprobleem, wat vergelykbaar is mẹt disleksie. ${ }^{25}$

Gewoonlik word die probleem van.'n sentrale taalwanbalans of -onvermoë in verband gebring met ' $n$ versteuring in die ontwikkeling en funksionering van die sentrale senuweesisteem. Dit is op die gebied van hoër kortikale integrasie waar die merendeel van die probleme gemanifesteer word. ${ }^{1,}{ }^{3}$ Arnold $^{1}$. be-; klemtoon die feit dat dit 'n afwyking is, wat die hoogste vlak van linguistiese formulasie en integrasie sal affekteer en Bradford ${ }^{3}$ voeg daarby dat enige toestand wat die harmoniese organisasie van serebrale aktiwiteite beinvloed ook probleme in verband met die ontvangs en koördinasie van visuele en ouditiewe indrukke sal veroorsaak. Dit sal weer die psigomotoriese stabiliteit van die persoon nadelig beinvloed. In hierdie geval sal die onderliggende PND, of meer spesifiek, die swak geintegreerde en onvolledige denkprosesse die oorsaak wees van die herhalende spraakpatroon, hersienings, huiwerings en stiltes, tussenwerpsels, artikulasie-afwykings, grammatikale verwarring en lees- en spellingprobleme. ${ }^{12}$

Uit 'n kubernetiese studie van die simptomatologiese beskrywings van PND aan die een kant, en stamel aan die ander kant, blyk dit dus asof daar 'n definitiewe verwantskap tussen die twee sindrome bestaan.'

\section{'N ETIOLOGIESE OOREENSTEMMING TUSSEN STAMEL EN PND}

Daar is ' $n$ baie noue verband tussen PND en stamel vasgestel deur eksperimentele bewyse, onder andere in verband met eienskappe van die senuiweesisteem, ${ }^{13}$ sekere biochemiese en formakologiese aanduidings ${ }^{9}, 14,26$ en die omlyning van die betrokke neurofisiologiese gebiede. ${ }^{7,10,16}$ Die volgende implikasie is dus voor die handliggend - dat in die geval van stamel die funksionering (kwalitatief en kwantitatief) van senuwee-oordrastowwe, tesame met selen organisme sensitiwiteit, tot 'n wanbalans in die funksionering van die twee opwekkingsisteme (die retikulêre en limbiese) kan bydra.

Die teorie, in verband met ' $n$ verhoogde adaptasiepeil (stelling) in die retikulêre formasie en 'n moontlike wanbalans in die wisselwerking tussen die twee sisteme, is ook van toepassing gevind op stamel. ${ }^{22}$ In hierdie geval (waarskynlik as gevolg van striatum-betrokkenheid) is die kenmerkendste simptome in die verbale kommunikasie-oo rdrag merkbaar. ${ }^{19,25}$

Dit gebeur meestal dat ondersoekers PND toeskryf aan kortikale wanfunksionering ${ }^{7}$ terwyl die probleem eerder in die retikulêre formasie gesoek behoort te word. Dieselfde mening word gehuldig in verband met die striatum en stamel. Die geweldige omvang en wisseling van simptome kan alleenlik verklaár word, indien die wisselwerking tussen die retikulêre en limbiese sisteme in ag geneem word.

\section{EMPIRIĖSE BEWYSE IN VERBAND MET STAMEL AS 'N VORM VAN PND}

In 'n onlangse navorsingsprojek ${ }^{22}$ is die hipotese gestel dat stamel een van die vorms is wat PND kan aanneem. Stamel' is dan ook beskou as die manifestasie van ' $n$ sentrale taalwanbalans, ${ }^{25}$ wat veral veruiterlik word in verbale 
kommunikasie-afwykings. Dit is toegeskryf aan afwykings in die koderingsprosesse, wat verbale uiting voorafgaan en al die verskillende kommunikasiekanale nadelig beinvloed.

'n Spraakkubernetiese model is opgestel, waarvolgens 'n psigoneurologiese verklaring van die verskillende kenmerkende verbale kommunikasie-simptome moontlik is.

Omdat dit egter alleenlik moontlik was om die hipotese deur empiriese bevindings te bewys, is ' $n$ omva ttende, maar intensiewe interdissiplinêre navorsingsprojek uitgevoer, waarin agt stamelaars, uit drie families, aan die volgende ondersoeke blootgestel is:

1. Volledige neurologiese ondersoeke

2. Elektroënkefalografiese ondersoeke

3. Intelligensie toetsing

4. Projeksietoetsing

5. Persepsie toetsing

6. Evaluasie van die kommunikasiesisteem en handeling (insluitende lees en spelling)

7. Evaluasie van skolastiese prestasies

8. Genetiese ontleding van familiegeskiedenisse met die oog op moontlike genetiese faktore.

Uit 'n kwalitatiewe analise van die toetsresultate, blyk dit dat al die agt proefpersone, in 'n mindere of meerdere mate, as persone met 'n psigoneurologiese disfunksie beskou kan word. Al die verskillende simptome, wat by PND voorkom is deur een of meer van die diagnostiese ondersoeke uitgelig by elkeen van die proef persone.

Afdoende bewyse is dus gevind dat stamel 'n vorm van PND is, met die kenmerkendste simptome gesentreer om spraak as kommunikasiemedium.

\section{KRITERIA VIR DIE INSLUITING VAN TOETSE IN DIE DIAGNOSTIESE BATTERY}

Aangesien daar reeds bewys is dat stamel 'n vorm van PND is, word die samestelling van 'n toetsbattery bepaal deur

a) die vermoë van sekere toetse om al die verskillende simptome van PND. uit te lig

b) die vermoë van sekere toetse om spesifiek die verbale kommunikasie abnormaliteite, kenmerkend van stamel, uit te lig.

Hier kan die diagnostikus gelei word deur die bevindings van vorige navorsers, tewete: Russell, Neuringer en Goldstein ${ }^{17}$; Schulman, Kaspar en Throne; ${ }^{18}$ Francis-Williams; ${ }^{4}$ Joubert; ${ }^{7}$ Weiss; ${ }^{25}$ Goldschmidt; ${ }^{5}$ en vele ander.

In die studie deur $\mathrm{Uys}^{22}$ is 'n omvattende toetsbattery gebruik wat die volgende ondersoeke en toetse ingesluit het:

\section{Genetiese Ondersoek}

Hierdie ondersoek dien alleenlik as aanduiding van familiale betrokkenheid. 'n 
Stamboom van elke familie word getrek, waarvolgens sekere afleidings, in verband met die voorkoms van stamel in families, gemaak kan word.

\section{Gevalsgeskiedenis}

Die Gevalsgeskiedenis behoort so beplan te word dat dit nie alleenlik alle moontlike etiologiese faktore insluit nie, maar ook 'n evaluasie van die waargenome simptome van die pasiënt. Aanduidings van familiale betrokkenheid kan hieruit verkry word. In breë trekke moet die volgende aspekte gedek word: Voorgeboortelike geskiedenis; perinatale geskiedenis; postnatale geskiedenis; ontwikkelingsmylpale; familiegeskiedenis; akademiese prestasie; oorsake en simptome van die probleem.

\section{Neurologiese Evaluasie}

Die neurologiese evaluasie kan in twee afdelings verdeel word, naamlik:

1. Die elektroënkefalografiese ondersoek, waar 'n twaalf-kanaal EEG-apparaat beduidende resultate sal lewer. Die bipolère metode van elektrodeplasing word aanbeveel. Hoewel daar in menslike EEG-studies gewoonlik van drie eksperimentele toetse gebruik gemaak word ${ }^{7}$, is daar vir die diagnose van stamel alleenlik twee toetse noodsaaklik. Photiese stimulasie vir die diagnose van epileptiese aanvalle word nie as noodsaaklik beskou nie. Die ,oë sluit-toets" stel die retikulère formasie en talamus in staat om alfa-sinchronisasie te bevorder en word dus aanbeveel. ${ }^{7}$ Die hiperventilasie-toets veroorsaak sametrekking van die bloedvate en kan ook aanduidend wees van moontlike epilepsie. ${ }^{23}$ 2. 'n Intensiewe neurologiese ondersoek behoort ingesluit te word sodat 'n kliniese evaluasie van die pasiënt moontlik is. In breë trekke moet die volgende aspekte hier gedek word: Algemene neurologiese evaluasie; funksies van die dominante hemisfeer; funksies van die nie-dominante hemisfeer; funksies van beide hemisfere; motoriese funksies; sensoriese funksies; reflekse.

\section{Psigometriese Evaluasic}

Die toetse wat in hierdie ondersoek gebruik word, kan in drie hoofgroepe verdeel word, volgens hulle vermoë om psigoneurologiese disfunksies aan te dui.

Intelligensie toetse. In die geval van Afrikaanssprekende pasiënte word die Wechsler-Bellevue Intelligensieskaal vir volwassenes en die Nuwe Suid-Afrikaanse Intelligensieskaal vir kinders aanbeveel. Vorige navorsing het reeds bewys gelewer ván die diagnostiese waarde van hierdie intelligensietoetse. ${ }^{4,15,17,24}$ Aan die hand van hierdie bevindings, word ook vir die diagnose van stamel 'n kwalitatiewe evaluasie van die resultate in die lig van die totale beeld aanbeveel. Spesiale toetse vir visuele persepsie, visuele geheue, oog-hand-koördinasie en dus psigoneu rologiese funksies: Die volgende toetse kan hier van waarde wees, naamlik Bender-Gestalt, Ellis Visual Designs, Albasterbord-toets, Grassi en Draw a Person. Die Bender Gestalt en Ellis Visual Designs kan mekaar in werklikheid vervang. ${ }^{2}$ In die toepassing van die Ellis Visual Designs kan die voorbeelde egter na 5 sekondes verwyder word, sodat die pasiënt op 'n geheuebeeld, dus integrasie van informasie, moet staatmaak. Hierdie toets lewer dus 
aanduidings van visucle geheuevermoëns (integrasie), terwyl die Bender Gestalt veral waarneming van weergawe tocts.

Die Grassi kan as aanvullende toets vir volwassenes gebruik word, ondat die toets nie diskriminerend genoeg is vir die toepassing op kinders nie. ${ }^{21}$

Persoonlikheidstoetse. Vir persoonlikheidsmeting kan dic Rorschach, Tematiese Appersepsietoets (TAT), Draw a Person (DAP) en Columbus Picture Analysis of Growth towards Maturity gebruik word.

Terwyl die Rorschach bruikbaar is by volwassenes, is die Columbus meer geskik vir kinders.

Al hierdic toe tse het reeds bewys gelewer van 'n vermoë om psigoneurologiese disfunksics aan te dui. ${ }^{18,6}$ Sommige van hierdie toe tse oorvleuel in 'n mate, maar kan ingesluit word waar sulke toetse vir meer as een doel gebruik word. Met die uitsondering van die DAP word die persoonlikheidstoetse vir die evaluering van persoonlikheid en die aanduiding van kompensatoriese meganismes gebruik. Die ander toetse is weer nuttig vir die aanduiding van psigoneurologiese disfunksies.

\section{Evaluasie van Ouditiewe Vermoëns}

Hierdie evaluasic berus op die resultate van twee groepe toetse.

Basiese ondersoeke is nodig vir die bepaling van die suiwertoondrempel, spraakontvangsdrempel en spraakdiskriminasievermoë. Aangesien daar in die geval van PND nie noodwendig perifere gehoorprobleme voorkom nie, kan die standaardprosedure by hierdie toetse gevolg word.

Spesiale ondersocke na verskillende aspekte van ouditiewe vermoëns is egter noodsaaklik in die diagnose van hierdie pasiënte. Aangesien daar nog 'n groot gebrek aan sulke toetse met Afrikaanse norms bestaan, word die Seashore Measures of Musical Talents hiervoor aanbeveel.

Die fisiese dimensies van ouditiewe seine kan beskou word as die produk van frekwensie- (psigies verteenwoordig as toonhoogte, terwyl die verskillende frekwensicsamestellings verteenwoordig word as timbre of toonkleur), intensiteits- (psigies verteenwoordig as luidheid) en temporale faktore (psigies verteenwoordig as tydsduur, ritme en reekse). Hierdie dimensies is almal ingesluit in die toets en kan anduidend wees van psigoneurologiese disfunksies. ${ }^{8}$ Hierdie toets bepaal hoofsaaklik twee aspekte van ouditiewe vermoëns, naamlik: die waarneming en diskriminasie van toonhoogte, luidheid, ritme, tydsduur en timbre, sowel as ouditiewe klankgeheue:

\section{Verbale Kommunikasje-ondersoek}

Aangesien daar geen gestandaardiseerde Afrikaanse toetse bestaan vir die objektiewe me ting van verbale kommunikasievaardighede nic, moet 'n ondersockwyse ontwerp word wat met 'n re delike mate van sekerheid kwalitatief ontleed kan word. Veral aangesien stamel hier ter sprake is, is dit noodsaaklik om hierdie aspekte meer volledig te ondersoek. 'n Drieledige toets word aanbeveel vir die evaluasie van lees, skryf en spraak as 'n kommunikasiemedium. 
Vir die leestoets kan die pasiënt cers 'n maklike leesstuk aangcbicd word waarmee sukses behaal kan word.

Dit sal egter die voorkoms van stamelsimptome na vore laat tree. ${ }^{25}$ Hicrdie stukke moet egter aangepas word by die pasiënt se ouderdom en akademiese stand.

'n Moeilike leesstuk sal weer bepaal of enige disleksie-elemente teenwoordig is, terwyl die stamelsimptome sal afneem (met die verhoogde konsentrasie en bewustheid).

Die skryfvermoë kan getoets word deur van die pasiënt te verwag om 'n stuk van 'n gedrukte voorbeeld af te skryf, te skryf volgens diktec en 'n spontane skryftaak. Hiermec word nie 'n volledige analise van die verskillende onvermoëns beoog nie, maar alleenlik die vasstelling van ouditief-motoriese, visueelmotoriese cn integrasic vermoëns.

Die evaluasie van spraak as 'n kommunikasiemedium vereis nie inisieel 'n volledige linguistiese analise nie - cerder is van waarde 'n stel toetsc om dic verskillende vlakke van abstrahering (integrasie) en proposisionering te onderskei en sodoende stamelsimptome uit te lig. So kan die volgende take van die pasiënt verwag word: Die beskrywing van 'n prent; storievertelling volgens 'n strokiesprent; storievertelling volgens een prent; spontane spraak.

Hierdie diagnostiese battery word as voldoende in omvang beskou, mits die ondersoekprosedure aan die volgende vereistes voldoen:

a) Die resultate moet 'n getroue weergawe van die pasiënt se beste pogings wees

b) Dit moet nie die pasiënt uitput nic

c) Aangesien dit 'n multidissiplinêre diagnostiese program is, bchoort deskundiges op clke gebied dic toetse af te neem.

d) Die omstandighede moet voldoen aan die vereistes van elke toets.

\section{EVALUASIE VAN DIE DIAGNOSTIESE PROGRAM}

Hierdie diagnostiese program is getoets aan die hand van agt pasiënte se resultate. In Tabel $1 \mathrm{kan}$ die vermoë van hicrdie toctse, om al dic verskillende simptome van PND uit te lig, duidelik gesien word. Die syfers in die kolomme is ' $n$ aanduiding van hoeveel pasiënte (uit agt) die spesifieke simptoom openbaar het.

'n' Evaluasie van die diagnostiese vermoë van die verskillende toetsé, hét die volgende gegewens aan die lig gebring:

1. Dic Neurologiese ondersocke het veral gedui op perseptueel-motoriese verstcurings, twy felagtige neurologiese tekens, en, in die geval van "die elektroënkef alogram- ondersoek, onreëlmatighede.

2. Die Intelligensictoctse is van groot diagnostiese waarde. Perseptueel-motoriese versteurings, emosionele probleme, twyfelagtige neurologiese tekens en integrasieversteurings (denke en geheueversteurings) het veral uit hierdie toetsresultate geblyk. 


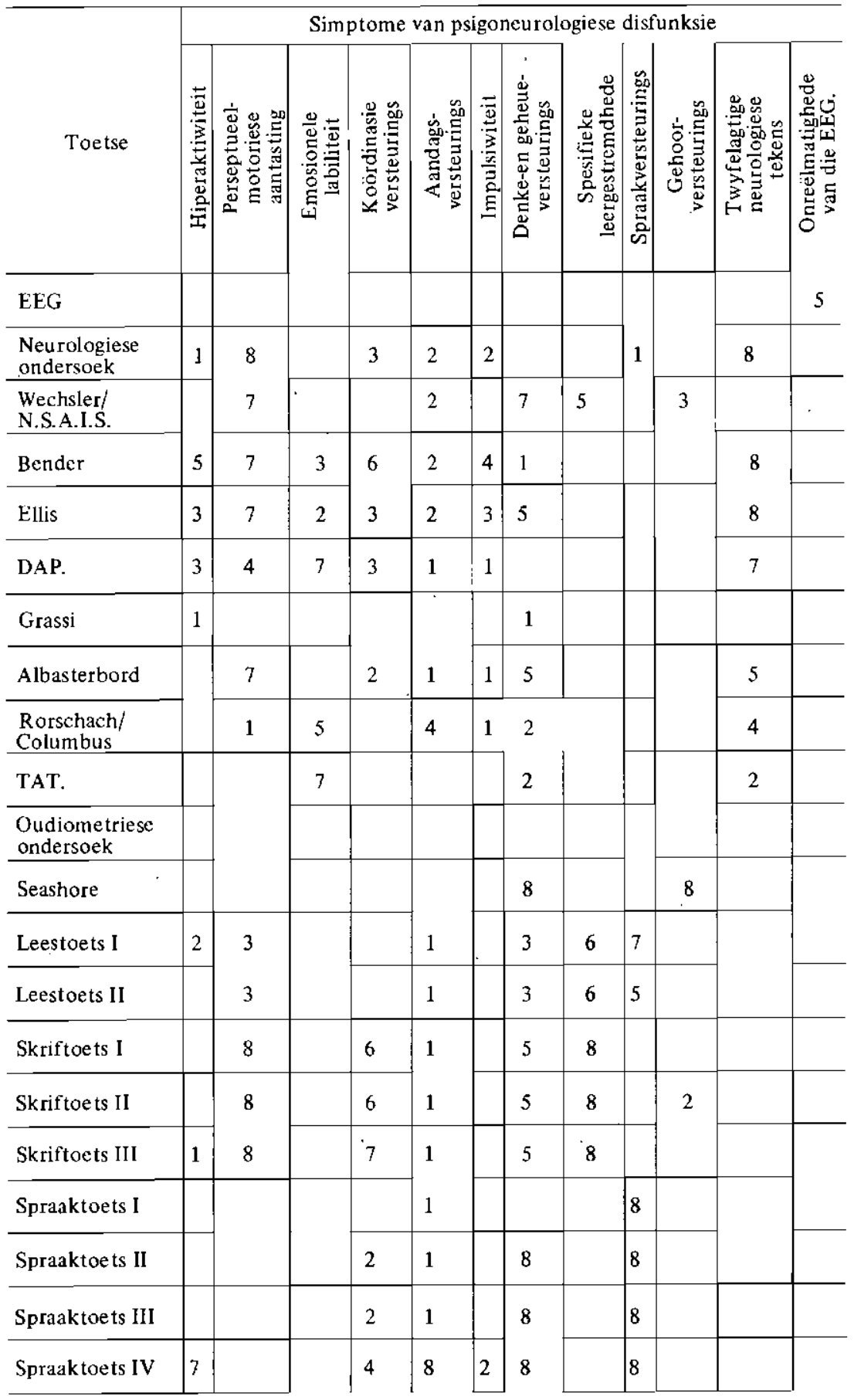

TABEL 1: Simptoomverspreiding na aanleiding van die Toetsresultate,

Tydskrif van die Suid-Afrikaanse Vereniging vir Spraak-en Gehoorheelkunde, Vol. 23, Desember 1976 
3. Toetse vir visuele vermoëns is veral van diagnostiese waarde ten opsigte van perseptueel-motoriese versteurings, motoriese koördinasieprobleme, aandagsversteurings en twy felagtige neurologiese tekens.

Dit blyk egter dat nie alle toetse vir visuele vermoëns diagnosties ewe goed is nie. Die Grassi het opmerklik minder simptome aangedui as die ander en in 'n mindere mate ook die DAP. Die Bender en Ellis het geblyk die beste diagnostiese waarde te hê.

4. Persoonlikheidstoetse dui veral op emosionele versteurings en kompensasiemeganismes. In 'n mindere mate kan hieruit ook inligting in verband met integrasieprobleme en aandagsversteurings verkry word. Die Rorschach en Columbus-toetse toon 'n beter diagnostiese vermoë as die TAT.

5. Toetse vir Ouditiewe vermoëns. Die Seashore toets is baie waardevol vir die bepaling van ouditiewe waarnemings-, diskriminasie- en geheuefunksies.

6. Leestoetse, veral waar dit verbind word met die ouditiewe en visuele funksies onderskeidelik, is aanduidend van integrasie-vermoëns, spesifieke leergestremdhede en ook verskillende spraakafwykings.

7. Die Skriftoetse het veral aanduidings gelewer van perseptueel-motoriese versteurings, koördinasie en integrasieprobleme, asook spesifieke leesonvermoëns.

8. Die Spraaktoetse het, as gevolg van die gradering, gedui op integrasieprobleme, aandagsversteurings en hiperaktiwiteit. Uiteraard het hierdie toetse die meeste inligting verskaf in verband met die voorkoms, verspreiding en aard van die verskillende spraakaf wy kings.

Alhoewel hierdie diagnostiese program dus toereikend blyk te wees vir die diagnose van stamel as 'n vorm van PND, word dit in die vooruitsig gestel dat meer objektiewe metingstoetse van groter nut sal wees, veral met die oog op kwantitatiewe analises van resultate. Daar is ' $n$ groot behoefte aan gestandaardiseerde toetse met Suid-Afrikaanse norms.

\section{VERWYSINGS}

1. Arnold, G.E., (1970): An Attempt to Explain the Causes of Cluttering with the L.L.M.M. Theory. Folia Phoniatrica. Vol. 22, No. 4-5, 247-260.

2. Aron, A.M. (1972): Minimal Cerebral Dysfunction in Childhood. $J$. Comm. Dis., Vol. 5, No. 2, bl. 142-153.

3. Bradford, D., (1970): Cluttering. Folia Phoniatrica. Vol. 22, No. 4-5, bl. $272-279$.

4. Francis-Williams, J., (1970): Children with specific Learning Difficulties. Pergamon Press, N.Y.

5. Goldschmidt, P., (1970): A Casuistic Model of a Logopedic Assessment in Private Practice. Folia Phoniatrica. Vol. 22, No. 4-5, bl. 289-300.

6. Gunzberg, H.C., (1955): Scope and Limitations of the Goodenough Drawing Test Method in Clinical Work with Mental Defectives. J. Clin., Psycho., Vol. 11, bl. 8-15.

7. Joubert, M.J., (1969): Psychoneurological Dysfunction in School-going - Children. Ongepubliseerde Proefskrif, Universiteit van Pretoria. 
8. Katz, J. (Ed.), (1972): Handbook of Clinical Audiology. The Williams \& Wilkins Co. Baltimore.

9. Krakowski, A.J., (1956): Amitriptyline in treatment of Hyperkinetic Children: a Double Blind Study. Psychosomatics. Vol. 6, bl. 355.

10. Moruzzi, G. \& Magoun, H.W., (1949): Brain Stem Reticular Formation \& Activation of the E.E.G. Electroencephalography \& Clinical Neurophysiology. Vol. 1, bl. 455.

11. Murray, C.H. de C., (1969): Verslag van die Komitee van Ondersoek na die Opvoeding van Kinders met Minimale Breindisfunksie. Dept. van Hoër Onderwys, Die Statsdrukker, Pretoria.

12. Mussafia, M., (1970): Various Aspects of Cluttering. Folia Phoniatrica. Vol. 22, No. 4-5, bl. 337-346.

13. Nebylitsyn, V., (1972): The Basic Properties of the Nervous System. Soviety Science Review. Maart, bl. 1 13-120.

14. Op't Hof, J., (1973): Die Genetiese Benadering tot Leergestremahede met Spesiale Verwysing na Spesifieke Leergestremdhede. Referaat gelewer bu doe Stogtomgslpmgres vam doe S.A. Vereniging vir Leer- en Opvoedingsmoeilikhede.

15. Reitan, R.M. \& Boll, T.J., (1973): Neurophysiological Correlates of Minimal Brain Dysfunction. Annals New York Academy Sciences. Vol. 205, bl. 65-88.

16. Routtenberg, A., (1968): The Two-Arousal Hypothesis: Reticular Formation \& Limbic System. Psychological Review. Vol. 75, No. 1, bl. 51-80.

17. Russell, E.W., Neuringer, C. \& Goldstein, G., (1970): Assessment of Brain Damage. A Neuropsychological Key Approach. Wiley-Interscience, N.Y.

18. Schulman, J.L., Kaspar, J.C. \& Throne, F.M., (1965): Brain Damage \& Behaviour. A Clinical-Experimental Study. Charles C. Thomas Springfield, III.

19. Seeman, M., (1965): Sprachstörungen bei Kindern. V.E.B. Verlag. Volk und Gesundheit, Berlin-Jena.

20. Seeman, M., (1970): Relations Between Motorics of Speech and General Motor Ability in Clutterers. Folia Phoniatrica. Vol. 22, No. 4-5, bl. 376-380.

21. Steyn, D., (1973): Kliniese sielkundige, Dept. Spraakwetenskap, Spraakheelkunde en Oudiologie, Universiteit van Pretoria. Persoonlike Onderhoude.

22. Uys, I.C., (1974): Psigoneurologiese Disfunksie: 'n Tipering volgens sekere Spraakpatologiese Verskynsels. Ongepubliseerde Proefskrif, Universiteit van Pretoria.

23. Van Der Merwe, H.P. (1973): Persoonlike Mededeling. Neuroloog, H.F. Verwoerd Hospitaal, Pretoria.

24. Wechsler, D., (1949): Manual Wechsler Intelligence Scale for Children. The Psychological Corporation, N.Y.

25. Weiss, D.A. (1964): Cluttering. Speech Foundation Series. PrenticeHall Inc., Englewood Cliffs, N.J.

26. Wender, P.H., (1971): Minimal Brain Dysfunction in Children. WileyInterscience, N.Y. 


\section{ACOUSTIMED}

(Pty.) Ltd. (Edms.) Bpk.

\section{SOUTH AFRICAN}

\section{MANUFACTURERS OF}

* Audiometers and sound pRoOf ROOMS

* SPEECH TRAINERS AND GROUP SYSTEMS

* HEARING AIDS AND COMPONENTS

WE PROVIDE A REPAIR SERVICE FOR ALL MAKES OF HEARING AIDS AND MANUFACTURE ALL TYPES OF EARMOULDS INCLUDING CLEAR SOFT MOULDS.

\section{PLEASE WRITE OR CALL:}

ACOUSTIMED (PTY) LTD., 302 SANDOWN CENTRE, MAUD ST., SANDOWN 2196, JOHANNESBURG.

P.O. BOX 782131, SANDTON 2146

RADIO TELEPHONE: DIAL 213361 ASK FOR CODE 564, CHANNEL 4. 